\title{
UM AMBIENTE MULTIMÍDIA E A RESOLUÇÃO DE PROBLEMAS DE FÍSICA
}

\section{Physics classroom activities through technological and communicative means}

\author{
Carlos Alberto Souza ${ }^{1}$ \\ Fábio da Purificação De Bastos ${ }^{2}$
}

Resumo: Atuou-se segundo os momentos metodológicos da investigação-ação escolar, desenvolvendo planejamentos, envolvendo os professores e os alunos no uso dos meios tecnológico-comunicativos nas atividades de sala de aula e especificando-se as ações escolares de Ciências da Natureza, Matemática e suas tecnologias. A comunicação, auto-reflexão e reflexão dos envolvidos no processo escolar foram incrementadas, compartilhando planejamentos e buscando consolidar o diálogo na sala de aula, problematizando situações, conceitos e a Resolução de Problemas, tendo como mediador o conhecimento científico-tecnológico, previamente tematizado e organizado.

Palavras-chave: resolução de problemas. ambiente multimídia. meios tecnológico-comunicativos.

\begin{abstract}
We act according to the methodological perspective of the Investigation-Action School, developing plans, involving teachers and students in the use of the Technological and Communicative Means in classroom activities and we specify school actions of Natural Science, Math and its Technologies. We improve communication, self-reflection of those involved in the school process, sharing planning, trying to consolidate the dialogue in the classroom, problematizing situations, concepts and how to solve the problems, having as a mediator the scientific-technological knowledge, previously thematized and organized.
\end{abstract}

Key words: solving problems. multi midia environment. technological and communicative means.

\footnotetext{
${ }^{1}$ Universidade Federal de Santa Catarina, Programa de Pós-Graduação em Educação Científica e Tecnológica; Colégio Agrícola de Camboriu, SC.E-mail: carlosal@ced.ufsc.br

${ }^{2}$ Professor, Universidade Federal de Santa Maria, Programa de Pós-Graduação em Educação, Santa Maria, RS.

E-mail:fbastos@ce.ufsm.br
} 
Souza, C. A.; De Bastos, F. P.

\title{
Perspectivas metodológicas no ensino-investigação-aprendizagem de Física
}

\author{
Na obra da Ciência só se pode amar o que se destrói, \\ pode-se continuar o passado negando-o, \\ pode-se venerar o mestre contradizendo-o. \\ Ai, sim, a Escola prossegue ao longo da vida.
}

(Bachelard, 1996, p. 309)

Temos atuado segundo os momentos metodológicos da investigação-ação escolar conhecida internacionalmente como movimento action-research (Carr, 1989; McNiff, 1988; Hodson, 1998; Elliott, 1978; Brunning, 2000; Poudrier, 2000) -, ou seja, dos passos - planejamento, ação, observação e reflexão - que formam a espiral cíclica-reflexiva de origem lewiniana (Carr e Kemmis, 1986). Enfatizamos, cada vez mais, o viés emancipatório das práticas escolares desenvolvidas, pautando-as pela interação educacional dialógico-problematizadora (Freire, 1983), que acreditamos sustentar a colaboração entre os sujeitos escolares.

Desenvolvemos planejamentos escolares (compreendidos como programação, resolução de problemas, atividades extraclasse e atividades de colaboração) envolvendo os professores e os alunos no uso investigativo nos meios tecnológico-comunicativos nas atividades de sala de aula e especificamos as ações escolares de Ciências da Natureza, Matemática e suas Tecnologias a cada hora-aula.

Este desenvolvimento, implementado colaborativamente com os envolvidos no processo escolar, gera atividades de ensino de Ciências da Natureza, Matemática e suas Tecnologias orientadas por planejamentos, subsidiando a etapa reflexiva do re-planejamento, cujo caráter avaliativo-deliberativo reorienta os ciclos seguintes. Assim, incrementamos a comunicação, auto-reflexão e reflexão dos envolvidos no processo escolar.

No AMEM-TEIA (Ambiente Multimídia para Educação Monitorada por Computador na perspectiva do Trabalho de Ensino-Investigação-Aprendizagem) desenvolvemos os planejamentos de acordo com os momentos pedagógicos de Angotti e Delizoicov (1990). Isto nos possibilita consolidar o diálogo na sala de aula, problematizando situações, conceitos e a Resolução de Problemas (RP), tendo como mediador o conhecimento científico-tecnológico, previamente tematizado e organizado pelo professor.

Compartilhamos planejamentos de modo a refletir sobre as ações a serem deflagradas, como emergir um saber teórico-prático e não somente o 'saber de experiência feito' (Freire, 1999).

Nesta fase, disponibilizamos a programação e consideramos sugestões dos alunos e dos professores colaboradores, ficando sob a responsabilidade do professor da disciplina as alterações que este julgar necessárias. Cabe lembrar que os professores colaboradores somente possuem acesso quando cadastrados pelo professor da disciplina. É este quem escolhe o(s) profissional(is) que pode $(\mathrm{m})$ contribuir com sua prática investigativa, pois reconhecemos os inúmeros problemas que os educadores enfrentam em seu labor. Aliás, 
Um ambiente multimídia e a resolução de problemas...

Temos sempre alunos ou salas que não se interessam em responder e é preciso tomar cuidado, pois os alunos têm uma 'inércia de trabalho' bastante grande e, se não há a cobrança do professor, perde-se muito tempo em classe, até que a atenção do grupo volte-se para a resposta às questões. (Carvalho et al., 1999, p. 87)

Destacamos que na Aplicação do Conhecimento disponibilizamos os problemas de Física na forma procedimental de Desafio inicial, Melhor solução escolar no momento e Desafio mais amplo (De Bastos e Müller, 1999). Segue aos problemas, no mínimo, uma questão ou novo problema, que procura envolver os conhecimentos científicos, situações sociais, objetos tecnológicos. Para exemplificar:

Desafio inicial: Como funciona uma lâmpada incandescente? O que a difere de uma fluorescente?

Desafio mais amplo: Que aparelho emite mais calor por segundo em uma sala sem janelas: um aquecedor de $100 \mathrm{~W}$ ou uma lâmpada incandescente de $100 \mathrm{~W}$ ?

Como critérios para a escolha do Desafio mais amplo sugerimos os conceitos unificadores (Angotti, 1991), garantindo a orientação, a organização curricular.

\section{Priorizando a problematização com o ambiente multimídia telemática}

A problematização permite o surgimento das idéias dos alunos, explicitando suas formas de pensar e a necessidade de adquirir conhecimentos que ainda não possuem. Para isso, é fundamental o diálogo que, "em qualquer hipótese, é a problematização do próprio conbecimento em sua indiscutivel relação com a realidade concreta na qual se gera e sobre a qual incide, para melhor compreendê-la, explicá-la, transformá-la" (Delizoicov, 1989, p. 7). Nesta fase, não fornecemos respostas às dúvidas que possam surgir. A prioridade é investigar as visões de mundo dos envolvidos, o que pensam durante a problematização. O AMEM-TEIA deve também possibilitar um canal de interação entre alunos e professor para eventuais dúvidas, a colaboração, o repasse das soluções para o professor e para os alunos, encaminhar novas tarefas, problematizar, sugerir e rever caminhos na RP. Criar estratégias para que o aluno possa, em se tratando de RP, descobrir a solução sob orientação do professor nos meios tecnológico-comunicativos, sem privá-los das 'novidades espirituais', como afirma Bachelard (1996). Justamente porque não podemos avançar nosso espírito científico recebendo os conhecimentos de alguém sem ao menos entender como e porque as coisas são desta forma.

A idéia de problematizar o conhecimento já construído pelo aluno foi definida também por Delizoicov (2001) em duas frentes: escolher e formular adequadamente os problemas e o processo pelo qual o professor estabelece o diálogo, a fim de identificar os conhecimentos prévios dos alunos, e localizar contradições e limitações nesses conhecimentos. Porque se o conhecimento científico e a elaboração de um pensamento rigoroso não podem prescindir de sua matriz problematizadora, então apreender esse conhecimento científico e o rigor desse pensamento filosófico não pode prescindir igualmente da problematização que deve ser feita em torno do próprio saber que o aluno deve incorporar.

Bachelard (1996) aponta a necessidade de todo ensino iniciar por uma catarse intelectual e afetiva capaz de favorecer a conscientização, ou seja, por meio de uma investigação 
possibilitar o conhecimento objetivo. Este momento pedagógico permite ao aluno conhecer sua forma de pensar e a consciência de que é necessária retificação constante de seu pensamento, porque assim também é a Ciência.

Evidentemente, o objetivo da problematização não se restringe a conhecer as idéias dos alunos. Plantamos um problema novo, uma curiosidade, um desafio, como preferimos falar, instigando-os para as atividades escolares que planejamos. Tornamos deles também a responsabilidade com o trabalho escolar que estamos desenvolvendo. Ressaltamos, ainda, que aqui as questões de ciência, tecnologia, sociedade e ambiente (CTSA) ${ }^{3}$ são exploradas, objetivando futuras ações nesta direção. A ação é orientada por um planejamento colaborativo e tanto os planejamentos por turma como os respectivos registros das aulas também ficam expostos no ambiente.

De acordo com Cachapuz et al. (2001), o ensino de CTSA valoriza os contextos reais dos alunos, a aprendizagem dos conceitos e os processos decorrentes de situações-problema cujas soluções procura-se encontrar.

Entretanto, discordamos da idéia de que "num ensino de CTS $A$ as situações-problema não são já a chamada 'resolução clássica de problemas', nem simplificaşões da realidade" (Millar, 1996, apud Cachapuz et al., 2001, p. 50). Para nós, a RP não pode limitar-se à RP de lápis e papel, mas também não pode-se dizer que não tem a ver com ela. Os problemas que observamos nas avaliações do Exame Nacional do Ensino Médio - ENEM - e dos próprios vestibulares do país demonstram a tendência já explícita nos Parâmetros Curriculares Nacionais do Ensino Médio. O nível dos problemas apresentados, também nos 'Provões' das áreas ligadas às Ciências da Natureza, Matemática e suas Tecnologias, também têm nos permitido compreender que não podemos abandonar a 'resolução clássica de problemas'. Até porque, "de maneira geral, a Física ensinada em Nivel Médio tem sido, historicamente, guiada pelos exames de vestibular das universidades mais prestigiadas" (Pietrocola, 2002, p. 2).

Estes tipos clássicos de problemas estão presentes no dia-a-dia do trabalho escolar, tanto pelas referências oficiais - Parâmetros Curriculares Nacionais, Exame Nacional do Ensino Médio, Sistema de Avaliação do Ensino Médio - como também nas obras didáticas - a maioria referenciada pelas políticas públicas oficiais - que sustentam o trabalho do professor, fortalecendo a cultura escolar. Um ensino-investigação-aprendizagem que estuda problemas mais amplos precisa também envolver a chamada 'resolução clássica de problemas'. Nossa intenção é alargar essa compreensão para que possamos ter uma forma melhor de tratar a RP em sala de aula, com mais possibilidade dos saberes construídos serem transferíveis e mobilizáveis para seu cotidiano.

Nesse novo quadro teórico consideramos que o currículo precisa valorizar as experiências de ensino-investigação-aprendizagem, permitindo e favorecendo o movimento de CTSA. Isto pode possibilitar um afastamento considerável do currículo tradicional de Ciências da Natureza, Matemática e suas Tecnologias,

\footnotetext{
${ }^{3}$ Conforme Cachapuz et al. (2001), a relevância de abordar situações-problema do cotidiano pode permitir refletir sobre os processos da Ciência e Tecnologia, bem como as suas inter-relações com a Sociedade e Ambiente, favorecendo a aprendizagem científica e tecnológica.
} 
Um ambiente multimídia e a resolução de problemas...

dominante nas nossas escolas, centrado na aprendizagem dos conceitos e nos processos da Ciência, na conviçãa e mesmo crença que mais tarde saibam utilizar tais conceitos aprendidos em contextos acadêmicos para dar respostas a situaçoes-problema em contextos do cotidiano; ou ainda, como eventuais pontos de partida para o desenvolvimento das atitudes, porém ao exclusivo serviço do cognitivo - quanto mais conceitos souber o aluno mais positivas serão as suas atitudes face às Ciências. (Cachapuz et al., 2001, p. 51. grifos nossos).

A problematização do conhecimento requer que possamos iniciar o processo de ensino-investigação-aprendizagem em S (sociedade) ou A (ambiente), mobilizando conceitos e processos. Intencionalmente, iniciamos por combinações variadas do tipo ACTS, ATCS, SCTA, permitindo ao professor decidir pela combinação mais apropriada, diretamente relacionada ao grupo de alunos, aos interesses dos envolvidos, aos objetivos do professor etc. Podemos assim destacar que

neste processo de construção de conceitos, não construidos analiticamente, mas entrelaçados em redes e em estruturas mais vastas que o professor ajuda, através de sinteses, a construir conceitos estruturantes - os alunos desenvolvem a criatividade e atitudes de interesse continuado para a aprendizagem. (Cachapuz et al., 2001, p. 51)

É nesta fase que realizamos uma análise aprofundada da situação-problema (Lopes, 2001). Porque superar a prática tradicional de Ciências da Natureza, Matemática e suas Tecnologias/Física pressupõe ter outro ponto de partida que não a apresentação de assuntos, as lições, bachelardianamente falando. Compreender que a problematização deve também permitir análise e aprofundamento da situação-problema, inclusive de situações físicas, é relevante do ponto de vista sócio-cultural e torna o ensino altamente motivador. Isto é fundamental para que os conhecimentos escolares estejam a serviço do tratamento das situações-problema, de seu aprofundamento e sua re-contextualização sócio-cultural.

Sabemos que no contexto da prática tradicional de Física os problemas estão prédefinidos, pré-determinados. É fácil encontrá-los nos livros-texto de Física, nos exames da área. Além das dúvidas dos alunos em sua resolução pouco se permite, pois a formulação de problemas não tem lugar. "E como a atividade de formular problemas é essencial para a aprendizagem, compreende-se que esta fique severamente prejudicada" (Lopes, 2002, p. 5, grifos nossos).

A perspectiva de trabalhar com os Momentos Pedagógicos (Angotti e Delizoicov, 1990), com base na análise e no aprofundamento da situação-problema, permite e encoraja a formulação de problemas que são atitude e atividade centrais para a eficácia da aprendizagem. Os registros podem contribuir para que possamos identificar se a análise e o aprofundamento da situação-problema têm condições de modificar a prática escolar. No momento, acreditamos que nesse processo os alunos estão se encaminhando para uma concepção de ensino-aprendizagem menos simplista e acabada, na qual precisam se empenhar para construir conhecimentos.

Algumas de suas expressões podem ilustrar um pouco do que apostamos e critica- 
mos. Por exemplo: "Não adianta alguém nos dar o conhecimento pronto"; "Nestas aulas a gente tem que pensar, não adianta fazer qualquer coisa ou ficar sem fazer nada e ganhar nota no final do ano"; "A construção do coletor solar nos fez penar muito e aprendemos o conteúdo fazendo, lendo e discutindo. A gente sabe porque não funcionou direito".

São afirmações que nos possibilitam refletir sobre a prática escolar desenvolvida. Mais do que isso, sobre a mudança efetiva na concepção dos alunos, contrastando com aquelas vivenciadas no cotidiano escolar. Portanto, o vínculo com a realidade e o conhecimento científico são fundamentais para a análise e o aprofundamento da situação-problema.

Conforme Lopes (2002), o pano de fundo dessa prática escolar tem dois aspectos fundamentais, aos quais somamos os dois momentos pedagógicos:

- Mediação das aprendizagens pelo professor em cada atividade e no conjunto das atividades em articulação com a avaliação formadora no processo e no final das atividades;

- Formulação de problemas em articulação com os saberes científicos dos alunos e do currículo, cada vez mais bem elaborado devido à análise e ao aprofundamento da situaçãoproblema; e

- Momentos pedagógicos que potencializam a análise e o aprofundamento da situação-problema, em um contexto problemático, um recorte temático em constante processo de investigação-ação escolar é que nos permite melhorar a formulação do problema. É neste movimento que o saber vai sendo construído pelos envolvidos.

No momento da problematização inicial já possuímos os nossos recortes temáticos, que são função de políticas públicas ${ }^{4}$. O importante aqui é não perder de vista nosso tema, o núcleo conceitual que vamos abordar, e nem as unidades temáticas que serão trabalhadas nesse tema. Tanto nesta fase como no desafio inicial, na RP, sobressai o caráter investigativo que desenvolvemos. A prática investigativa depende desses momentos. Por acreditarmos que a teoria orienta a prática escolar que desenvolvemos e é, ao mesmo tempo orientada por ela, supomos que existe um movimento de reformulação constante de ambas.

Estes momentos - problematização inicial e desafio inicial - carregam possibilidades de introduzirmos os equipamentos geradores ${ }^{5}$, tendo em vista que não podemos nos ater ao paradigma da linguagem. Trabalhando com esses objetos tecnológicos podemos descobrir o que o aluno pensa sobre ele, seu funcionamento, seus princípios, relações que estabelece entre ciência, tecnologia e sociedade. Ou, mesmo, que conhecimentos utiliza quando manuseia este objeto. Portanto, esta prática de ensino-investigação-aprendizagem requer atenção constante do investigador. A qualquer momento podem surgir elementos essenciais para a investigação e ação docente.

Observação e atenção constante aos procedimentos dos alunos são fundamentais para descobrirmos suas dificuldades, o que ele sabe e o que não sabe fazer, onde seu conhecimento não é suficiente, em que precisamos orientá-lo, se o TEIA (Trabalho de Ensino-Inves-

\footnotetext{
${ }^{4}$ Tanto pelos Parâmetros Curriculares Nacionais, na Proposta Curricular do Estado de Santa Catarina, como pelas avaliações ENEM e SAEM.

${ }^{5}$ De Bastos, 1990.
} 
Um ambiente multimídia e a resolução de problemas...

tigação-Aprendizagem) (Souza, 2004) está cumprindo seu papel, o que precisa ser modificado, melhorado... Além disso, orientados pelos referenciais teóricos podemos constantemente reorganizar o TEIA. Assim, o quadro do algoritmo é o seguinte:

\begin{tabular}{|c|c|}
\hline COMPREENSÃO & \\
\hline \multicolumn{2}{|l|}{ Desafio Inicial: Problema } \\
\hline $\begin{array}{l}\text { Relacione seu(s) interesse(s) e } \\
\text { transforme o enunciado. }\end{array}$ & $\begin{array}{l}\text { (Qual(is) o(s) interesse(s) na situação-problema? Transforme o } \\
\text { enunciado deste problema tradicional e fechado - se assim estiver } \\
\text { - para um problema aberto, utilizando linguagem cotidiana) }\end{array}$ \\
\hline Aponte sua(s) hipótese(s). & $\begin{array}{l}\text { (Faça uma análise qualitativa, apontando as grandezas físicas } \\
\text { necessárias, as leis, os princípios físicos envolvidos, as atividades } \\
\text { experimentais possíveis de implementar na sala.) }\end{array}$ \\
\hline \multicolumn{2}{|l|}{ Melhor solução escolar no momento: } \\
\hline O que temos? & $\begin{array}{l}\text { (Que grandezas físicas estão envolvidas? Quais as condições? } \\
\text { Utilize notação científica simbólica e observe o sistema } \\
\text { internacional de unidades) }\end{array}$ \\
\hline O que queremos? & $\begin{array}{l}\text { (Que grandezas físicas queremos encontrar? Utilize notação } \\
\text { científica simbólica e fique atento ao sistema internacional de } \\
\text { unidades das mesmas) }\end{array}$ \\
\hline Esboce um esquema da situação. & $\begin{array}{l}\text { (Esboce um esquema gráfico ou modelo da situação-problema que } \\
\text { seja ilustrativo da mesma e um referencial) }\end{array}$ \\
\hline $\begin{array}{l}\text { PLANEJAMENTO } \\
\text { Organize a solução do problema. }\end{array}$ & $\begin{array}{l}\text { Escreva a(s) equação(ões) relacionada(s) com a situação- } \\
\text { problema, identificando as respectivas grandezas físicas que } \\
\text { podem ser medidas e/ou calculadas na aula) }\end{array}$ \\
\hline $\begin{array}{l}\text { EXECUÇÃo } \\
\text { Desenvolva a resolução. }\end{array}$ & $\begin{array}{l}\text { (Desenvolva a resolução do problema literalmente - } \\
\text { operacionalizando os conceitos-chave, se necessário por meio de } \\
\text { uma atividade experimental -, fazendo a substituição numérica, de } \\
\text { preferência, somente no final) }\end{array}$ \\
\hline $\begin{array}{l}\text { RETROSPECÇÃo } \\
\text { Descreva o(s) ponto(s) fundamental(is) } \\
\text { na resolução. } \\
\text { O que significa o resultado? }\end{array}$ & $\begin{array}{l}\text { (Faça um retrospecto da resolução completa. É possível chegar } \\
\text { ao resultado por outro caminho? Quais os pontos determinantes } \\
\text { da resolução efetuada? Explicite a compreensão da(s) teoria(s), } \\
\text { lei(s), princípio(s) físico(s) fundamental(is) Como se integraram: } \\
\text { conceitos-chave, resolução do problema e atividade } \\
\text { experimental?) } \\
\text { (Qual o significado do resultado encontrado na realidade em que } \\
\text { vivemos? A solução tem sentido físico? O resultado encontrado é } \\
\text { fundamental para compreender o princípio de funcionamento do } \\
\text { sistema? Tendo em vista a produção da existência humana, o que } \\
\text { pode ser otimizado?) }\end{array}$ \\
\hline $\begin{array}{l}\text { PROSPECÇÃo } \\
\text { Desafio mais amplo: questão ou } \\
\text { problema }\end{array}$ & $\begin{array}{l}\text { Utilizando o que você aprendeu até agora nas aulas de Física é } \\
\text { possível resolver esta questão ou problema? Por quê? Relacione o } \\
\text { conhecimento físico trabalhado no problema anterior com esta } \\
\text { situação. }\end{array}$ \\
\hline
\end{tabular}

Algoritmo proposto para resolução de problemas (Souza, 2004, p.167) 
O ponto fundamental para iniciarmos um conteúdo com os alunos é a problematização inicial, buscando a análise e o aprofundamento da situação-problema num contexto problemático, favorecendo a formulação do problema. A situação pode ser constantemente aprofundada, conforme interesse dos envolvidos e objetivos do professor. Nada impede que após a aplicação do conhecimento, utilizando o TEIA, o professor retorne à problematização, procurando aprofundar mais seus problemas, e envolva aspectos que ainda não conseguiu trabalhar.

$\mathrm{Na}$ organização do conhecimento sistematizamos o conhecimento de Ciências da Natureza, Matemática e suas Tecnologias necessário para a compreensão do tema e da problematização inicial. Ao perceber quais as superações, informações e habilidades necessárias para dar conta das questões inicialmente colocadas e as contradições surgidas na problematização inicial, o professor propõe atividades que possam permitir avanços. Priorizamos, nesse momento, os centros das contradições explicitadas pelas visões de mundo dos alunos, tensionando as soluções apresentadas com o conhecimento científico-tecnológico produzido e disponível. Este tensionamento das visões científico-tecnológica e cotidiana é fundamental para viver rupturas cognitivas e romper, conscientemente, as situações-limite vivenciadas. Para isso, será preciso desenvolver definições, conceitos e relações organizados segundo o eixo curricular conceitual unificador ${ }^{6}$ para permitir a apreensão de novos conhecimentos, não partilhados pela turma, que os ajudem a perceber a realidade, agora sob uma nova ótica. Neste momento a sistematização dos conhecimentos de Ciências da Natureza, Matemática e suas Tecnologias é prioridade, permitindo visão de mundo.

Cabe lembrar que não se deve compreender o processo de ensino-aprendizagem como uma troca de informações entre duas ou mais pessoas. As técnicas de ensino empregadas pelo professor devem privilegiar o esforço, o estudo e a investigação dos envolvidos. Devemos ser coerentes com a idéia de Bachelard (1996), deixando de apresentar a Ciênciacomo um conhecimento fácil e recordar a citação de Kuhn (1977), tendo em vista que também aprendemos a teoria por meio da RP - desde que reconheçamos a imbricação entre a aprendizagem conceitual com o processo de RP, elaborando e estimulando a RP que exija análise em sua resolução (Leonard et al., 2002).

O esforço pessoal dos alunos é determinante para a aprendizagem dos conhecimentos científicos. Para isso, precisam estar mais conscientes do processo de aprendizagem e motivados para tal. Isto inclui saber por que aprender Física é importante. Discussões como essas podem ser muito produtivas para o professor, que não deve ignorá-las:

Os alunos sabem como aprendem melhor? Têm pensado quais suas maiores virtudes e dificuldades? Entendem por que os conceitos são importantes? Sabem por que é útil estruturar o conhecimento? Comunicar sobre a aprendizagem ajuda a motivar os alunos e a mantê-los ativos no processo de aprendizagem. (Leonard et al., 2002, p. 397)

\footnotetext{
${ }^{6} \mathrm{~A}$ organização curricular é orientada pelos conceitos unificadores, categorias presentes na busca de teorias científicas pelos praticantes das ciências naturais, supradisciplinares, 'que transitam' pelas várias áreas deste conhecimento científico, presentes na Física, Química e Biologia e nas outras áreas de caráter transdisciplinar e norteador da análise dos fenômenos naturais (Angotti, 1991).
} 
Um ambiente multimídia e a resolução de problemas...

Isto reforça nossa compreensão de que não precisamos nos sentir na obrigação de cobrir 'todo' o conhecimento relacionado ao tema trabalhado. É evidente que um bom planejamento também incorpora bons problemas para os alunos: cria expectativa para o perfil dos problemas didáticos, e nos leva a concluir que não há necessidade de pensarmos ou planejarmos uma infinidade de problemas aos alunos.

Os trabalhos que temos desenvolvido possibilitam afirmar quanto os programas curriculares são destituídos de conhecimentos culturais. "Na minha opinião, bastante vazios de conteúdos culturais. A diferença entre um e outro está nos 'saberes que importam saber" (De Bastos, 2001a, p. 1). Afinal, por que priorizar recortes temáticos como movimento retilíneo e uniforme e movimento retilíneo uniformemente variado, leis de Newton, termologia, óptica geométrica, eletrostática e resistores em detrimento das leis de conservação? Será que são as temáticas mais relevantes para o Ensino Médio?

Os conteúdos escolares se impõem de tal forma que se instalam e se mantém como 'paradigmas de ensino', mesmo distantes dos paradigmas de investigação. Referem-se, na maioria das vezes, a uma Ciênciade um ou dois séculos passados. Ficam limitados pela aprendizagem e carregam marcas ideológicas, embora pouco reconhecidas pelos professores e alunos (Angotti, 1991).

Como De Bastos (2001), propomos descentrar a discussão de conteúdos para conceitos. Sendo universais (Angotti, 1991), os conceitos potencializam transformações escolares. Talvez, dessa forma, tenhamos mais sucesso no trânsito entre os mundos da vida e da escola. Alerta Angotti (1991) que os conteúdos escolares sagrados, fragmentados e encerrados em 'garrafas do saber', limitam a prática do professor e dificultam o 'trânsito cidadão'.

$\mathrm{Na}$ aplicação do conhecimento abordamos sistematicamente o conhecimento que vem sendo incorporado pelo aluno. Para isso, o professor poderá propor um retorno às questões iniciais para analisar, interpretar e explorar tanto as situações que determinaram seu estudo como outras que não estejam diretamente ligadas ao motivo inicial, mas são explicadas pelo mesmo conhecimento. Portanto, um momento avaliativo para professor e alunos. Neste, também, há que se romper com os mitos e trabalhar a relação ciência, tecnologia, sociedade e ambiente.

É no terceiro momento pedagógico que apontamos para a necessidade de desenvolvermos e incentivarmos a RP. Colocamos, assim, os alunos diante de desafios, cuja operacionalização conceitual, mediada pelo conhecimento científico-tecnológico produtor de transformações pode produzir rupturas com sua cultura primeira. O intuito é envolver os alunos na busca de solução para o desafio proposto. Além disso, podemos investigar mais de perto as dificuldades que os alunos apresentam na RP. O que permite guiar e transformar, ou seja, mediar a prática escolar para garantir a aprendizagem dos alunos. É evidente que o envolvimento dos alunos na RP é prioridade. Caso fiquem numa atitude passiva perdemos o caráter desafiador do momento.

\section{A resolução de problemas e a prática de laboratório}

Ao reconhecer que "a transformação efetiva do ensino habitual de Ciências precisa algo mais do 
que o simples reconhecimento de algumas de suas carências mais visiveis ou que a introdução de inovações puntuais, restritas a um só aspecto" (Gil-Pérez, 1999, p. 312), passamos a considerar que o questionamento da distinção clássica entre teoria, práticas de laboratório e RP é oportuno e pode contribuir com as estratégias didático-metodológicas que estamos desenvolvendo.

Para Gil-Pérez et al. (1999, p. 313) "a orientação da aprendizagem como uma investigação dirigida priva de sentido a esta separação que, convém notar, não guarda paralelismo algum com a atividade cientifica real'. Segundo os autores, se pretendemos proporcionar uma visão correta do trabalho científico aos alunos devemos trabalhar RP, teoria e práticas conjuntamente. Distanciá-los pode se converter em um obstáculo, pois sabemos que na atividade científica estes aspectos aparecem imbricados.

Apesar dos fatores que frustram as práticas de laboratório (falta de instalações e material adequado, número excessivo de alunos, ilustração das teorias ...), busca-se, nelas, o rompimento com o ensino puramente livresco e solucionar dificuldades na aprendizagem de Ciências da Natureza, Matemática e suas Tecnologias (Gil-Pérez et al., 1999). Entretanto, " $n u$ merosos autores têm destacado que as práticas de laboratório aparecem como 'receitas' que transmitem uma visão deformada e empobrecida da atividade cientifica" (Gil-Pérez et al., 1999, p. 314). Apesar disso, quando se estabelece uma discussão sobre a natureza do trabalho científico, segundo os autores os professores que concebem as práticas de laboratório como receitas ilustrativas vêem a necessidade de concebê-las como vinculadas ao tratamento de um problema relevante, à construção de hipóteses etc.

Esta relativa facilidade para transformar os trabalhos práticos segue escondendo, em nossa opinião, uma visão reducionista da atividade cientifica, que associa prioritariamente investigação a trabalho experimental, e que tem atuado como obstáculo na renovação de outros aspectos do processo de ensino-aprendizagem das Ciências. (Gil-Pérez et al., 1999, p. 314)

Isto se integra ao que discutimos a partir de Bachelard (1996), tendo em vista que o conhecimento se origina de um problema, ou seja, que é resposta a uma pergunta. Bachelard (1996) também atribui importância às práticas de laboratório, alertando-nos sobre os cuidados com as experiências pois, conforme já mencionamos, este autor afirma que é fácil recorrer ao encantamento, ao lúdico, fazendo experiências que divertem, mas não instruem.

Gil-Pérez et al. (1999) também criticam a RP de lápis e papel, afirmando que não se ensina a RP, ou seja, não se ensina a enfrentar situações desconhecidas. Ao contrário, ensinamse soluções desconhecidas e que não geram nenhum tipo de dúvida nem exigem tentativas. Ainda por cima, pretendemos que os alunos percebam claramente os caminhos a seguir. Isto significa que

Pretendemos converter o problema em um não-problema. Conseqüentemente, os estudantes podem aprender dita solução e repeti-la diante de situações praticamente idênticas, mas não aprendem a abordar um verdadeiro problema $e$ qualquer pequena mudança lhes supõe dificuldades insuperáveis, provocando manipulações não significativas de dados, fórmulas e incógnitas e, muitas vezes, $\boldsymbol{o}$ abandono. (Gil-Pérez et al., 1999, p. 314. grifos nossos) 
Um ambiente multimídia e a resolução de problemas...

Ao se preocupar com a dispersão dos alunos, mas reconhecendo sua necessidade de aprenderem a formular problemas, construir hipóteses, investir na RP que o professor considera importante para a aprendizagem, atribuir significado ao resultado encontrado etc, os passos do TEIA contemplam a transformação do enunciado. Esta reorientação na RP, utilizando também os meios tecnológico-comunicativos, por si só constitui uma atividade desafiadora. Aliada às práticas de laboratório, resgata a ação dos alunos, transformando-a em conhecimentos ao compreender os procedimentos realizados. Em contrapartida, a ausência de uma orientação específica como o TEIA pode representar uma lacuna nesse sentido. Sendo assim,

Se diluem assim as marcadas diferenças que, no ensino por transmissão de conhecimentos já elaborados, se dão entre as práticas de laboratório e os problemas de lápis e papel. Mas é possivel ir além neste processo de integração, estendendo-o o que no jargão docente denominamos de teoria. (Gil-Pérez et al., 1999, p. 317)

É importante reconhecer a necessidade do diálogo nas aulas de Ciências da Natureza, Matemática e suas Tecnologias/Física. Para tanto, o professor deve explorar as idéias que surgem dos alunos, tanto na problematização inicial, como na organização e aplicação do conhecimento. Diante disso, Solomon (apud Gil-Pérez et al., 1999) defende que "após impulsionar a expressão de um conjunto de opiniōes particulares, o professor não pode simplesmente rechaçar as que não se ajustam à teoria vigente. Desse modo deixaria de ser possivel um diálogo aberto" (p. 317).

Gil-Pérez et al. (1999) ainda destacam que a aprendizagem das Ciências é concebida não como uma simples mudança conceitual, mas como uma mudança às vezes conceitual, metodológica e atitudinal. O que implica "uma completa integração da $\langle$ teoria $\rangle$, às $\langle$ práticas $\rangle$ e aos <problemas > em um único processo de construção de conbecimentos científicos" (Gil-Pérez et al., 1999, p. 317). O que constitui "um forte apoio às propostas de aprendizagem das Ciências como um processo de investigação dirigida" (p. 317).

O emprego desse procedimento didático-metodológico - desafio inicial, melhor solução escolar no momento e desafio mais amplo - no TEIA tem mostrado potencial para desafiar e engajar concretamente os alunos na RP, exigindo dos mesmos o trânsito pela açãoreflexão-ação para sua elaboração. Além disso, essa etapa também tem a função de auxiliar nos planejamentos das próximas aulas, constituindo componente avaliativo-deliberativo na estrutura programática das aulas.

Uma nova ação escolar do professor requer também estímulo à colaboração dos alunos. Priorizar tal colaboração exige a inter-relação e a interdependência dos seres humanos, que deverão ser solidários ao buscar caminhos para uma vida mais fraterna e coletiva. Além disso, trabalhos que valorizam a colaboração possibilitam a perspectiva escolar dialógicoproblematizadora de Freire (1985), pela qual os professores, ao ensinarem, aprendem; e os alunos, ao aprenderem, também ensinam.

\section{Estratégias didático-metodológicas para resolução de problemas de Física}

Problematizar a didática habitual de RP é tarefa dos formadores de professores. Po- 
rém, afirmar que "umas das primeiras atividades a realizar conduza, precisamente, a pôr em questão tal didática, a fazer sentir 'na própria carne' as deficiências do ensino habitual de resolução de problemas" (Gil-Pérez et al., 1992, p. 7, grifos nossos), já se distancia do que temos observado na formação de professores.

Ao pretendermos que os professores se apropriem de uma determinada prática escolar precisamos vivê-la com eles, problematizando-a e refletindo sobre ela. Essa formação deve se dar na ação, enquanto vivência do processo, e não distante dela. É por isso que os desafios propostos aos professores, permitindo que explicitem suas etapas de RP, também sugerem que os mesmos ainda não incorporam os passos fundamentais dessa atividade. Como não se interessaram ainda por ela, ou seja, não deram a devida importância para esta prática - apesar de todo ensino de Física girar em torno disto - os alunos também não se apropriam, obtendo pouco rendimento nas avaliações e desprezo por esta atividade.

A orientação na resolução pode variar de um aluno para outro, porém é indiscutível que quem esteja resolvendo um problema tenha em mente diretrizes que possam ser aplicadas em diferentes situações. Entre as dificuldades relacionadas à RP, destacamos o operativismo mecânico com que se aborda habitualmente os problemas, inclusive por parte dos professores, o que reforça a pouca eficiência dos alunos. Além disso, "estimula um operativismo abstrato, carente de significado, que pouco pode contribuir a uma aprendizagem significativa. Um tratamento superficial que não se detém na clarificação dos conceitos" (Gil-Pérez et al., 1992, p. 9), o que favorece confusões entre conceitos, dificultando a compreensão. Mesmo quando se chega a resultados corretos, pode-se favorecer visões confusas e errôneas. Os inúmeros problemas resolvidos sobre queda de corpos próxima da superfície da Terra não impedem que os alunos continuem a pensar que corpos com o dobro de massa cheguem primeiro ao solo. Assim, "os problemas 'corretamente' resolvidos não têm permitido questionar a idéia ingênua da influência da massa". Ou, "os problemas, em vez. de serem ocasião privilegiada para construir e aprofundar os conhecimentos, se convertem em reforco de erros conceituais e metodológicos" (Gil-Pérez et al., 1992, p. 9, grifos nossos).

Afirmar que os professores também têm dificuldade na RP ou que carecem de uma didática mais eficiente para esta atividade não resolve a situação levantada. O fato de perceberem suas dificuldades nessa tarefa não confere a eles mais ou menos conhecimento sobre o assunto. Portanto, não consideramos que a 'tomada de consciência' possa se dar a partir da resolução de um problema, muito menos de cinemática clássica.

Estamos de acordo com o fato de que os dados dos enunciados induzem os alunos ao manejo das equações, dados e incógnitas, sem uma reflexão qualitativa, muito menos de hipóteses. Devemos pensar que os problemas desenvolvidos em sala de aula podem cobrir esse vácuo que insiste em não favorecer a aprendizagem de formulação de problemas e a prática de emissão de hipóteses. Esta última contempla a RP abertos e aproxima essa prática das tarefas fundamentais do trabalho científico.

Portanto, aprender a transformar os enunciados pode ser uma tarefa não só do professor, mas também dos alunos, tendo em vista que o ensino de Ciências da Natureza, Matemática e suas Tecnologias deve favorecer a aprendizagem de formulação de problemas (Bachelard, 1996). Isso não impede de trabalharmos, também, com problemas que carregam dados e precisões dos enunciados habituais.

Nossas ações investigativas ocorreram em contextos diversos com professores em formação e alunos do Ensino Médio demarcando, com eles, o espaço de sala de aula como 
Um ambiente multimídia e a resolução de problemas...

local de investigação. Durante a disciplina de Didática I da Física, na UFSM ${ }^{7}$, segundo semestre de 2001, após estudo de textos sobre RP de Física com o professor Fábio ${ }^{8}$ discutimos uma proposta de algoritmo para RP a ser trabalhada pelos licenciandos e analisada durante o estágio com alunos do Ensino Médio. No primeiro semestre de 2002, na disciplina Didática II da Física, UFSM, o professor agendou horários individuais para trabalharmos uma primeira versão do TEIA com os licenciandos. Procuramos identificar se eles (após o estágio), implementaram um fazer alternativo, investigando e valorizando a prática de RP de Física, investiram na qualidade dos problemas e utilizaram o algoritmo que organizaram durante a disciplina. Nesse período também contactamos os alunos de Prática e Metodologia de Ensino de Física da UFSC, do professor Angotti ${ }^{9}$, discutindo a prática escolar em RP de Física e apresentando a primeira versão do TEIA.

A partir do segundo semestre de 2002 também passamos a trabalhar com o ambiente multimídia AMEM e o algoritmo para RP de Física na disciplina de Didática I na UFSM. O objetivo era investigar uma didática alternativa para a RP com IAE, recuperando o componente extraclasse com o auxílio dos meios tecnológico-comunicativos para fortalecer o diálogoproblematizador na sala de aula. Os textos de Gil-Pérez et al. (1992) e o TEIA têm contribuído nesta direção. Organizamos e enviamos eletronicamente para os alunos desafios propostos e problematizados em sala de aula. Com isso também objetivamos consolidar a cultura informática na prática escolar dos alunos e dos professores.

O contato com o professor Valdir, de uma escola particular de Itajaí/SC, inaugurou uma nova ação investigativa. Para o professor, o trabalho poderia favorecer os alunos que não acompanhavam as aulas de Física, principalmente na primeira série, com muita dificuldade em $\mathrm{RP}$, mesmo participando de aulas de reforço no período vespertino desde o início do ano letivo.

Desenvolvemos algumas atividades com o professor e alunos. Trabalhamos o TEIA e o programa em sua primeira versão e procuramos identificar o potencial que ele possui nessas situações, principalmente porque consideramos que ela não é diferente em outras instituições de ensino.

Também atuamos em um curso de especialização em Metodologia de Ensino para a Educação Básica em Júlio de Castilhos/RS. Utilizamos o TEIA numa situação bastante diferenciada. Além de a maioria dos professores atuar no Ensino Fundamental, também identificamos que as formações são bastante variadas: licenciatura curta e plena, universidades particulares e públicas, abrangendo História, Letras, Artes, Geografia, Estudos Sociais, Matemática e Ciências Naturais.

Discutimos os três momentos pedagógicos, a necessidade de investigar o pensar e o agir dos alunos e, em seguida, passamos a mostrar e discutir os planejamentos da disciplina de Didática I, na qual atuamos colaborativamente, projetados com auxílio de um datashow. O fato

\footnotetext{
${ }^{7}$ Universidade Federal de Santa Maria/RS.

${ }^{8}$ Prof. Dr. Fábio da Purificação de Bastos da UFSM/RS, Centro de Educação, PPGE/CE.

${ }^{9}$ Prof. Dr. José André Peres Angotti da UFSC/SC, Centro de Educação, PPGE/CED PPGECT/CFM.
} 
de termos estudado o texto sobre os momentos pedagógicos e a explicitação dos planejamentos favoreceu o diálogo sobre nossas práticas educativas e a percepção de que os termos utilizados para os passos do TEIA precisam ser revistos, pois carregam o 'jargão' da Física, inclusive repensando as caixas explicativas de cada passo. Nossa compreensão é que o TEIA poderia favorecer a RP de forma multidisciplinar.

Em 2003 concentramo-nos no trabalho com os alunos do Ensino Médio do Colégio Agrícola/UFSC, onde atuo ${ }^{10}$ como professor da disciplina de Física, e nas análises sobre as investigações realizadas. Assim, procuramos compreender os problemas (e soluções) que a prática escolar apresenta.

A discussão sobre a necessidade de um algoritmo para RP (Souza, 2004) foi provocada e aprofundada nos encontros com os envolvidos. Nossa prática escolar também tem gerado reflexões que conduzem a priorizar tal desenvolvimento, apesar de Gil-Pérez et al. (1992) descreverem "um modelo de resolução de problemas como investigação" (p. 13, grifos nossos) e afirmarem "que as orientações precedentes não constituem um algoritmo que pretenda guiar passo a passo a atividade dos alunos" (p. 17, grifos nossos). Consideramos que existem procedimentos gerais na RP de Ciências da Natureza, Matemática e suas Tecnologias (Zylbersztajn, 1998) e estes precisam ser incorporados pelos alunos.

\section{Considerações finais}

Consideramos importante a aproximação entre didática de RP e investigação-ação e a prática cotidiana de RP. Assim, a valorização de cada problema como um momento único de investigação pode trazer mais qualidade ao ato pedagógico e, para distanciar-se de uma solução puramente técnica, a didática de RP proposta deve ser compreendida.

A partir do modelo de RP como investigação proposto por Gil-Pérez et al. (1992), analisamos o algoritmo que construímos (Souza, 2004). Estamos assumindo que desenvolvemos uma seqüência de passos orientadores para a resolução de um problema, principalmente quando se trata de ensino-investigação-aprendizagem de RP. Além disso, também concordamos que a tarefa necessita de monitoramento constante. Cabe ao professor, numa atitude de permanente investigação, estar atento à forma como cada aluno resolve os problemas. Isto para quem deseja realmente modificar a prática escolar e obter mais sucesso no processo de RP.

Consideramos que a proposta teórico-metodológica precisa valorizar a colaboração tanto dos alunos, como de professores envolvidos no processo de investigação-ação escolar buscando harmonia e desenvolvimento das dimensões técnica, humanística, científica, política e ética: um trabalho colaborativo entre pessoas e instituições de ensino que, antes das redes de comunicação, não possuíam meios para se comunicar ou trabalhar em grupo com velocidade e eficiência. A colaboração permite desenvolver autonomia e espírito crítico e, mesmo que não prescinda das tecnologias, acreditamos que amplifica e potencializa suas possibilidades em situações escolares.

${ }^{10}$ Prof. Dr. Carlos Alberto Souza, Colégio Agrícola de Camboriú/UFSC/PPGECT. 
Um ambiente multimídia e a resolução de problemas...

O ambiente multimídia favorece a colaboração entre os sujeitos geograficamente distantes e estimula os alunos, talvez por estarem mais abertos às tecnologias de seu tempo. Entretanto, apesar da popularização do uso da internet, ainda são muitas as limitações técnicas (velocidade e manutenção da rede, número e manutenção de computadores) para professores e alunos, dificultando o acesso ao ambiente e, evidentemente, a comunicação via rede entre professor-aluno e aluno-aluno.

Comprovamos que o TEIA no computador provoca uma mudança na forma como os alunos do Ensino Médio encaram a RP de Física, suscitando o diálogo com o professor e entre si, mesmo que ele gire em torno das dificuldades conceituais de resolver o problema, da falta de compreensão dos passos e sua função ou dúvida sobre algum aspecto fenomenológico, o que muitas vezes não ocorre durante as aulas tradicionais, mesmo com os livros didáticos.

É importante ressaltar que ao utilizar o TEIA na sala de aula a conduta pedagógica tradicional, na qual o professor resolve os problemas para os alunos, passou a ser reorientada, em prol de um trabalho colaborativo e mais esforço por parte dos mesmos.

Nossas conquistas educativas a partir do segundo semestre têm criado esperança para nossas ações futuras. Se no primeiro semestre de 2003 as colaborações dos alunos estiveram abaixo dos $20 \%$, a partir do segundo, e principalmente no início do quarto bimestre, passamos a atingir percentuais de $70 \%$. É evidente que a proximidade do final do ano letivo contribui para isso, pois os alunos relacionam o cumprimento das tarefas escolares com a aprovação. No entanto, já percebemos mais qualidade nas colaborações, mais adensamento conceitual, eles preocupados, por exemplo, em indicar referências bibliográficas e sites para o trabalho que desenvolvemos sobre o motor a combustão interna. Em 2004, os índices estiveram pouco acima de $70 \%$ e observamos boas respostas (auto-reflexão organizada) às atividades extraclasse, demonstrando mais atenção, envolvimento e preocupação dos alunos com a qualidade de seus trabalhos nas aulas de Física.

Quanto à participação dos professores colaboradores, também enfrentamos a dificuldade da interação eletrônica no ambiente virtual, instalado no servidor do Laboratório de Ensino de Física do Colégio Agrícola e acessado via site gratuito. Esta colaboração tem sido pouco efetivada, mas já foi possível reconhecer sua função para o trabalho de grupo e a mudança da prática escolar docente.

A proposta didático-metodológica para trabalhar pedagogicamente RP em sala de aula está sustentada pela percepção que temos da mudança da concepção de formação de professores. Não basta nos distanciarmos da educação bancária e avançar para uma prática dialógica. A RP e as estratégias didático-metodológicas propostas são possibilidades que devem ser investigadas, discutidas, analisadas, reorganizadas e aprofundadas. Assumimos que o mesmo deve ser dito a respeito da utilização dos meios tecnológico-comunicativos em sala de aula. É evidente que a problemática não se esgota neste trabalho, nem temos esta pretensão, mas esperamos que possua elementos para subsidiar discussões e apresentar possibilidades para novas investigações.

Há uma perspectiva esperançosa apontada por Gil-Pérez et al. (1992), a partir do trabalho de RP com atividades experimentais e teoria. Isso precisa estar bastante organizado pelo professor, pois orienta os alunos para aprender a planejar e a conduzir suas ações de acordo com o planejamento. Uma forma de orientar o 'pensar' dos alunos, em busca de um pensamento científico. Assim, poderão conseguir, ao final da atividade, argumentar sobre a 
Souza, C. A.; De Bastos, F. P.

confiabilidade das conclusões atingidas. Entretanto, as práticas de RP + atividade experimental + teoria devem ser priorizadas na formação inicial e permanente. Além disso, devem-se trabalhar os problemas abertos, potencializando contribuir com o entendimento das idéias fundamentais da área.

\section{Referências}

ANGOTTI, J. A. P. Fragmentos e totalidades no conhecimento científico e no ensino de Ciências. São Paulo, 1991. Tese (Doutorado em Educação) - Faculdade de Educação/ Instituto de Física, Universidade Estadual de São Paulo, São Paulo.

Física. 2. ed. São Paulo: Cortez, 1991.

ANGOTTI, J. A. P.; DELIZOICOV, D. Metodologia do ensino de Ciências. 2.ed. São Paulo: Cortez, 1990.

BACHELARD, G. A formação do espírito científico: contribuição para uma psicanálise do conhecimento. Tradução: Estela dos Santos Abreu. Rio de Janeiro: Contraponto, 1996.

BRUNNING, C. Professional development using action research. Disponível em: < http:/ /www.mcb.co.uk/services/conferen/nov95/ifal/paper1.htm>. Acesso em: 27 set. 2000.

CACHAPUZ, A. F.; PRAIA, J. F.; JORGE, M. P. Perspectivas de ensino. Org. CACHAPUZ, A. F. Formação de Professores. 2.ed. Porto: Martins \& Irmão, 2001. (Coleção Formação de Professores/Ciências, textos de apoio n. 1).

CARR, W. Action-research: ten years on. Journal of Curriculum Studies, v. 21, n. 1, p. 8590, 1989.

CARR, W.; KEMMIS, S. Becoming critical: education, knowledge and action research. Brighton: Falmer Press, 1986.

CARVALHO, A. M. P.; SANTOS, E. I.; AZEVEDO, M. C. P. S.; DATE, M. P. S.; FUJII, S. R. S.; NASCIMENTO, V. B.; FUJII, S. R. S.; NASCIMENTO, V. B. Termodinâmica: um ensino por investigação. São Paulo: FEUSP, 1999. 
Um ambiente multimídia e a resolução de problemas...

DE BASTOS, F. P. Organização conceitual da melhor solução educacional no momento. Disponível em: <http://amem.ce.ufsm.br>. Acesso em: 23 mar. 2003.

DE BASTOS, F. P.; ABEGG, I. Redes e conhecimento científico na escola. In: MION, R. A..; SAITO, C. H. (Coords.). Investigação-ação: mudando o trabalho de formar professores. Ponta Grossa: PR: Gráfica Planeta. p. 91-9.

DE BASTOS, F. P.; MÜLLER, F. M. Criando desafios em informática. In: ESCOLA DE VERÃO SOBRE INVESTIGAÇÃO-AÇÃO EDUCACIONAL, 4., Santa Maria, 1999. Atas... Santa Maria, 1999.

DELIZOICOV, D. Problemas e problematizações. In: PIETROCOLA, M. (Org.). Ensino de Física: conteúdo metodológico, metodologia e epistemologia numa concepção integradora. Florianópolis: Ed. da UFSC, 2001. p. 125-50.

Uma no cravo, outra na Ferradura. 1989. Trabalho não publicado. ELLIOTT, J. What is action-research in schools? Journal of Curriculum Studies, v. 10, n. 4, p. 355-357, 1978.

FREIRE, P. Pedagogia da autonomia: saberes necessários à prática educativa. 13.ed. São Paulo: Paz e Terra, 1999.

Pedagogia do oprimido. 14.ed. Rio de Janeiro: Paz e Terra, 1985.

Educação como prática da liberdade. 18.ed. Rio de Janeiro: Paz e Terra, 1983.

GIL-PÉREZ, D.; FURIO MAS, C.; VALDES, P.; SALINAS, J.; MARTINEZ-TORREGROSA, J.; GUISASOLA, J.; GONZALEZ, E.; DUMAS-CARRE, A.; GOFFARD, M.; CARVALHO, A. M. P. Tiene sentido seguir distinguiendo entre aprendizaje de conceptos, resolución de problemas de lápiz y papel y realización de prácticas de laboratorio?. Enseñanza de las Ciencias, v. 17, n. 2, p. 311-20, 1999.

GIL-PÉREZ, D.; MARTINEZ TORREGOSA, J.; RAMIREZ, L.; DUMAS CARRE, A.; GOFARD, M.; PESSOA, A. M. Questionando a didáctica de resolução de problemas: elaboração de um modelo alternativo. Caderno Catarinense de Ensino de Física, v. 9, n. 1, p. 7 19, 1992.

HODSON, D. Becoming critical about practical work: changing views and changing practice through action research. International Journal Science Education, v. 20, n. 6, p. 683-694, 1998.

KUHN, T. A tensão essencial. Lisboa: Edições 70, 1977. 
Souza, C. A.; De Bastos, F. P.

LEONARD, W. J.; GERACE, W. J.; DUFRESNE, R. J. Resolución de problemas basada en el análisis. Hacer del análisis y del razonamiento el foco de la enseñanza de la Física. Enseñanza de las Ciencias, v. 20, n. 3, p. 387-400, 2002.

LOPES, J. B. Perspectivar novas modelizações da prática relevantes para o conhecimento profissional do futuro professor de Física. Disponível em: http:/ / www.educ.fc.ul.pt/ recentes/mpfip/pdfs/bernardinolopes.pdf>. Acesso em: 02 jul. 2002.

McNIFF, J. Action research: principles and practice. Hong Kong: MacMillan Education Ltda, 1988.

PIETROCOLA, M. Contribuição: visibilidade social e contatos com a área de educação. In: VIANNA, D. M.; PEDUZZI, L. O. Q.; BORGES, O. N.; NARDI, R. (Orgs.). Atas do Encontro de Pesquisa em Ensino de Física, 8. São Paulo: SBF, 2002. (CD-Rom, arquivo: COCD1_1.pdf).

POUDRIER, C. AR: CPS the pedagogical model of action-research for the community problem solving. European Environmental Education Newsletter. Disponível em: <http:// www3.sympatico.ca/claude/poudrier/arcps/htm>. Acesso em: 10 mar. 2000.

SOUZA, C. A. Investigação-ação escolar e resolução de problemas de Física: o potencial dos meios tecnológico-comunicativos. Florianópolis, 2004. Tese (Doutorado em Educação) - Programa de Pós-Graduação em Educação, Universidade Federal de Santa Catarina.

ZYLBERSZTAJN, A. Resolução de problemas: uma perspectiva Kuhniana. In: ENCONTRO DE PESQUISA EM ENSINO DE FÍSICA, 6., 1998, Florianópolis. Anais... Florianópolis, 1998. $1 \mathrm{CD}$.

Artigo recebido em maio de 2006 e aceito em novembro de 2006 